\title{
PRIMARY PANCREATIC SARCOMA
}

\section{Matheus Dorigatti Soldatelli ${ }^{1}$, Abraão Kupske², Caroline Lorenzoni Almeida Ghezzi ${ }^{1,2}$}

A 54-year-old female patient presented with nonspecific abdominal pain that had been gradually worsening for approximately two months. She denied significant weight loss. Physical examination showed a distended abdomen and a painful palpable mass in the epigastrium. Laboratory studies showed a white blood cell count of $27,000 \mathrm{cells} / \mathrm{mL}$, a C-reactive protein level of $199 \mathrm{mg} / \mathrm{dL}$, a CA 19-9 level of $656 \mathrm{U} / \mathrm{mL}$, and a hemoglobin count of $10.9 \mathrm{~g} / \mathrm{dL}$, as well as normal values of gamma-glutamyl transpeptidase, total bilirubin, alkaline phosphatase, hepatic transaminases, and amylase.

A computed tomography (CT) scan of the abdomen identified a large, heterogeneous, expansive lesion with a geometric center in the pancreatic head and body, measuring $6.4 \times 5.1 \times 3.2 \mathrm{~cm}$, with irregular margins and heterogeneous enhancement with hypodense central areas suggestive of necrosis/liquefaction. This lesion showed signs of vascular involvement, especially portal vein invasion, and involvement of the branches of the celiac trunk and mesenteric vessels, contraindicating surgical treatment (Figures $1 \mathrm{~A}$ and $1 \mathrm{~B}$ ). The patient underwent a new CT scanning two months later, which demonstrated a significant increase of the pancreatic lesion, lymph node enlargement, and the development of hepatic lesions compatible with metastases. The compression and invasion of the main bile duct was also observed, determining the dilatation of intra- and extrahepatic bile ducts, demonstrated by percutaneous transhepatic cholangiography (Figure 2A, B, and C). A biopsy of the lesion showed an undifferentiated, high-grade pleomorphic malignancy with necrosis. The immunohistochemical profile confirmed the diagnosis of pancreatic sarcoma with positivity for the cell-surface vimentin (CSV) marker (Figure $3 \mathrm{~A}$ and B). The patient died after a few weeks due to significant clinical worsening.

Primary pancreatic sarcomas are extremely rare entities, accounting for less than $0.1 \%$ of all pancreatic neoplasms ${ }^{1}$. They originate from the mesenchymal tissue of pancreatic support, and the leiomyosarcoma subtype is the most frequently reported ${ }^{2}$. This neoplasia usually presents poor prognosis due to late diagnosis and accelerated growth relative to other pancreatic neoplasia ${ }^{1,3}$. The pancreatic head is the most commonly involved site, followed by the tail and body, and it occurs more frequently in younger individuals ${ }^{3}$. Clinically, patients may present with weight loss, palpable abdominal mass, epigastric pain, nausea and vomiting, similar to other pancreatic diseases, thus being unspecific to sarcomas ${ }^{1-3}$. On CT scanning, the findings include a bulky, heterogeneous mass and, with peripheral enhancement after contrast injection, pseudocystic masses are also described.

CSV is an exclusive marker of sarcoma regardless of its tissue origin ${ }^{4}$. The prognosis is influenced by the patient's age, tumor size, the presence of tumor necrosis, and vascular invasion. The curative treatment is surgical - extensive surgical resection should be advocated, even when morphologic results show a low-grade lesion ${ }^{2}$. The tumor is likely to metastasize to the liver but not to regional lymph nodes. The role of chemotherapy and radiotherapy in pancreatic sarcoma has not been well studied ${ }^{5}$.
Clin Biomed Res. 2018;38(1):93-95

1 Radiology Service, Hospital de Clínicas de Porto Alegre. Porto Alegre, RS, Brasil.

2 Radiology Service, Hospital Moinhos de Vento. Porto Alegre, RS, Brasil.

Corresponding author: Matheus Dorigatti Soldatelli md.soldatelli@gmail.com Radiology Service, Hospital de Clínicas de Porto Alegre (HCPA) Rua Ramiro Barcelos, 2350. 90035-903. Porto Alegre, RS, Brasil. 


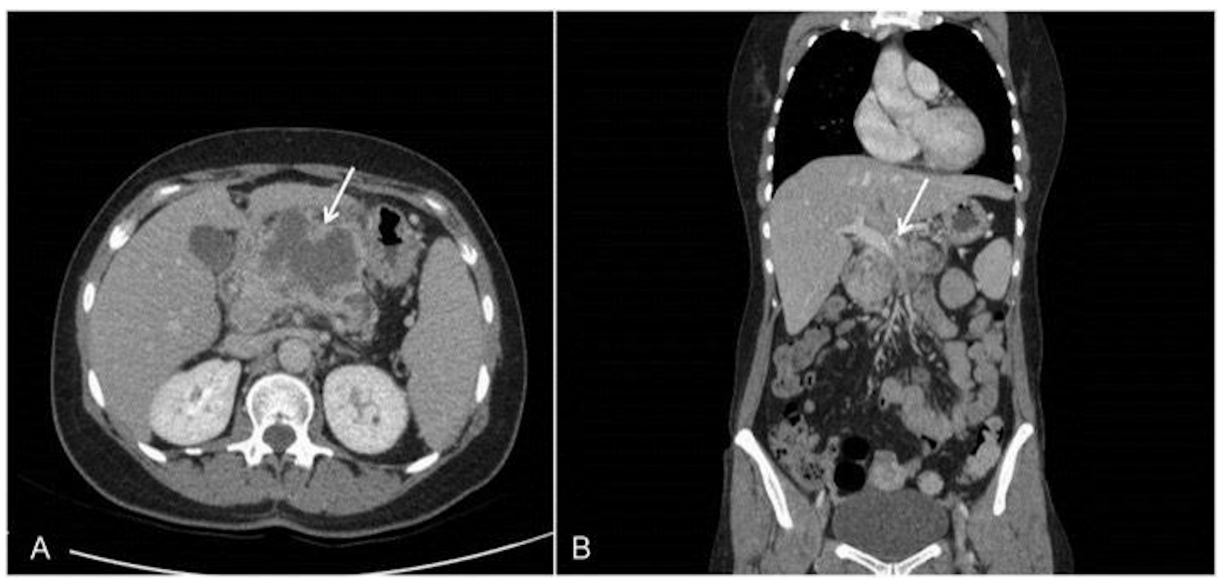

Figure 1: An initial computed tomography scan in axial $(A)$ and coronal $(B)$ planes shows a heterogeneous mass centered within the pancreatic body (arrows) extending to the pancreatic head with signs of vascular involvement, especially the mesenteric vessels and branches of the celiac trunk.
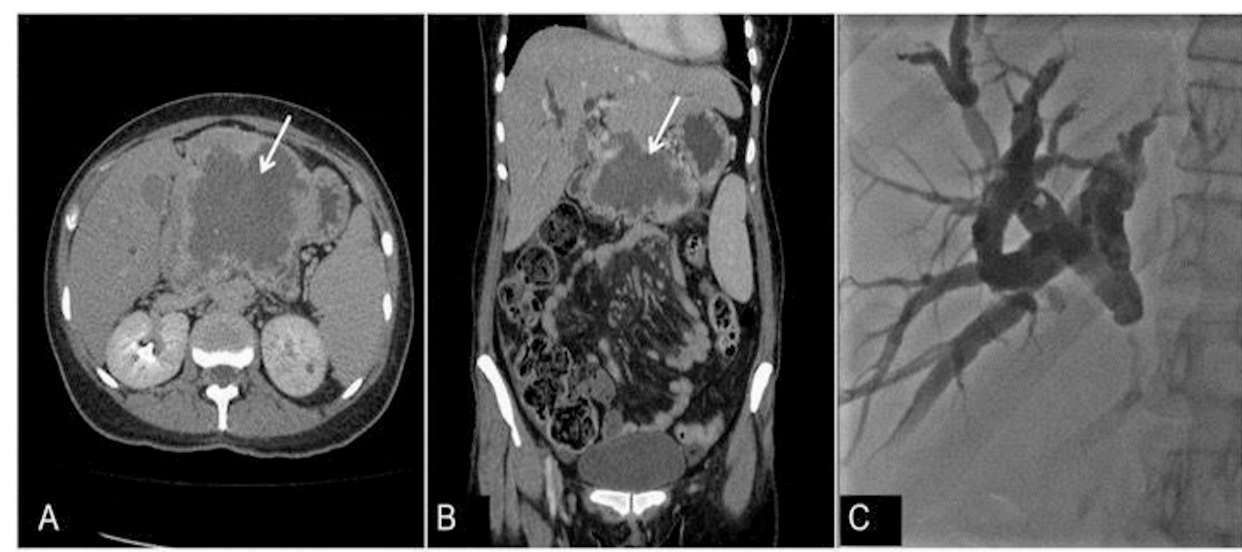

Figure 2: ACT scan in the axial (A) and coronal $(B)$ planes shows an important increase of the pancreatic heterogeneous mass (arrows), as well as invasion of adjacent structures. Cholangiography (C) shows dilatation of the intrahepatic bile ducts and abrupt decrease in the caliber of the common bile duct at the level of the hepatic hilum.
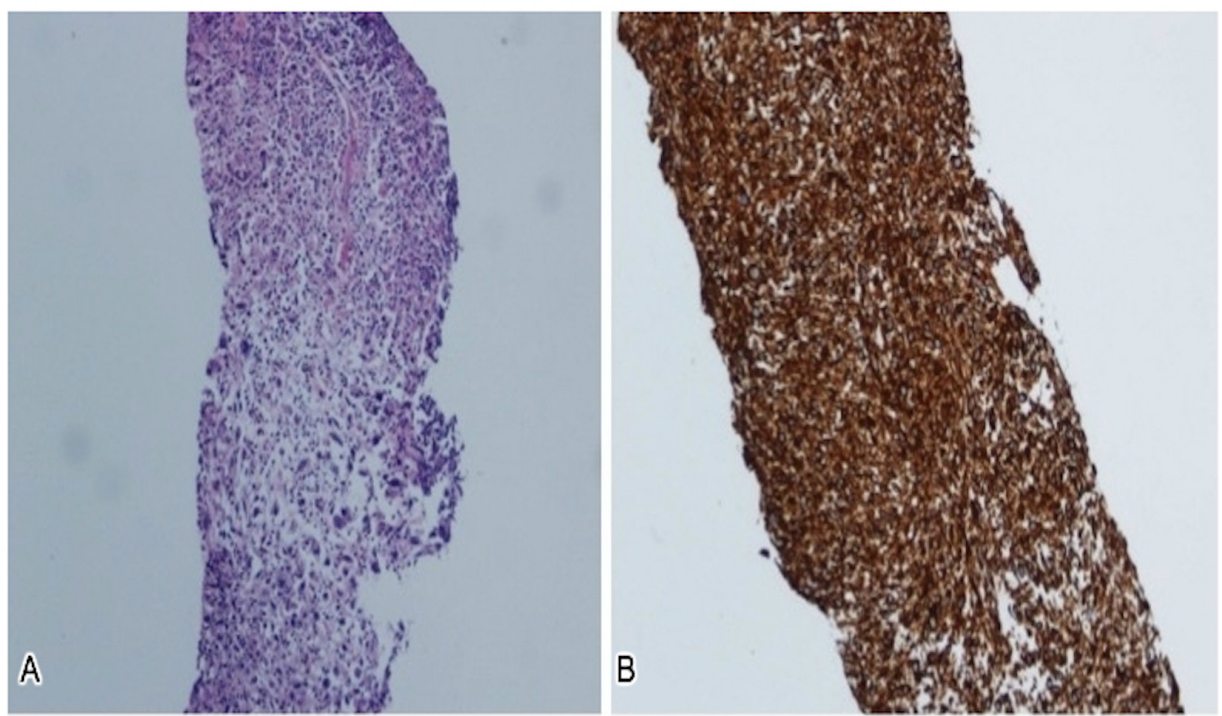

Figure 3: A: Undifferentiated, pleomorphic, high-grade malignant neoplasm with necrosis. B: Immunohistochemical profile compatible with undifferentiated, pleomorphic, high-grade sarcoma. 


\section{Conflicts of Interest}

The authors declare no conflicts of interest.

\section{REFERENCES}

1. Ambe P, Kautz $C$, Shadouh $S$, Heggemann S, Köhler L. Primary sarcoma of the pancreas, a rare histopathological entity. A case report with review of literature. World $J$ Surg Oncol. 2011;9(1):85. http:// dx.doi.org/10.1186/1477-7819-9-85. PMid:21812970.

2. Zhang $\mathrm{H}$, Jensen $\mathrm{MH}$, Farnell MB, Smyrk TC, Zhang L. Primary leiomyosarcoma of the pancreas: study of 9 cases and review of literature. Am J Surg Pathol.
2010;34(12):1849-56. http://dx.doi. org/10.1097/PAS.0b013e3181f97727. PMid:21107091.

3. Feather HE, Kuhn CL. Total pancreatectomy for sarcoma of the pancreas. Ann Surg. 1951;134(5):904-12. http://dx.doi. org/10.1097/00000658-19511100000015. PMid:14885957.

4. Satelli A, Mitra A, Cutrera JJ, Devarie M, Xia X, Ingram $\mathrm{DR}$, et al. Universal marker and detection tool for human sarcoma circulating tumor cells. Cancer Res. 2014;74(6):1645-50. http://dx.doi. org/10.1158/0008-5472.CAN-131739. PMid:24448245.

5. Omidvari S, Nasrolahi $\mathrm{H}$, Kadkhodaei B, Hamedi SH, Ahmadloo N, Ansari $M$, et al. Primary pancreas sarcoma, optimal treatment and prognostic factors. Rep Radiother Oncol. 2015;2:e5126.

Received: Oct 09, 2017 Accepted: Jan 17, 2018 